Squibb, Omar Jabado Shareholder of: Bristol-Myers Squibb, Employee of: Bristol-Myers Squibb, Sarah Hu Shareholder of: Bristol-Myers Squibb, Employee of: Bristol-Myers Squibb, Roy Fleischmann Grant/research support from: AbbVie, Akros, Amgen, AstraZeneca, Bristol-Myers Squibb, Boehringer, IngelhCentrexion, Eli Lilly, EMD Serono, Genentech, Gilead, Janssen, Merck, Nektar, Novartis, Pfizer, Regeneron Pharmaceuticals, Inc., Roche, Samsung, Sandoz, Sanofi Genzyme, Selecta, Taiho, UCB, Consultant of: AbbVie, ACEA, Amgen, Bristol-Myers Squibb, Eli Lilly, Gilead, GlaxoSmithKline, Novartis, Pfizer, Sanofi Genzyme, UCB, Michael Weinblatt Grant/research support from: Amgen, Bristol-Myers Squibb, Crescendo, Lily, Sanofi/ Regeneron, Consultant of: AbbVie, Amgen, Bristol-Myers Squibb, Crescendo, Gilead, Horizon, Lily, Pfizer, Roche, Sean Connolly Shareholder of: Bristol-Myers Squibb, Employee of: Bristol-Myers Squibb, Michael A Maldonado Shareholder of: Bristol-Myers Squibb, Employee of: Bristol-Myers Squibb, Sheng Gao Shareholder of: Bristol-Myers Squibb, Employee of: Bristol-Myers Squibb DOI: 10.1136/annrheumdis-2020-eular.2208

\section{FRI0577 VITAMIN D LEVEL IN HEALTHY CANARIAN ADULT POPULATION}

A. García Dorta ${ }^{1}$, H. D. Marta ${ }^{1}$, L. Medina Vega² , J. J. Villacampa Jiménez², J. J. Bethencourt Baute ${ }^{1}$, A. Alvárez Díaz ${ }^{3}$, C. Luna-Gomez ${ }^{4}$, F. Álvarez Reyes ${ }^{4}$, S. Machín García ${ }^{5}$, S. Bustabad ${ }^{1} .{ }^{1}$ Hospital Universitario de Canarias, Rheumatology, Tenerife, Spain; ${ }^{2}$ Hospital Universitario de Canarias, Laboratory, Tenerife, Spain; ${ }^{3}$ Hospital Virgen de las Nieves, Rheumatology, La Palma, Spain; ${ }^{4}$ Hospital Universitario Nuestra Señora de Candelaria, Rheumatology, Tenerife, Spain; ${ }^{5}$ Maternal and child Hospital, Rheumatology, Gran Canaria, Spain

Background: Vitamin D (VitD) was first used to treat rickets in children in depressed urban areas of England, due to malnutrition and lower sun exposure. During the last decade its use has become widespread in western societies because it has been associated with lower risk of suffering from multiple diseases and there is also a lack of consensus in establishing adequate levels for the general population. Regarding the beneficial effects of VitD, well-designed current observational studies are calling them into question and many authors believe that levels of $30 \mathrm{ng} / \mathrm{mL}$, adopted as optimal, are overestimated ${ }^{1-2}$. All this has led many individuals who come to our consultations to use supplements without scientific evidence of their benefits.

Objectives: The main objective was to determine the distribution of VitD levels in the healthy canarian population, an area with high solar radiation and stratified according to demographic factors (age, sex and place of residence). As a secondary objective, the study was established to determine prevalence of hyperparathyroidism hypercalcemic in the canarian population.

Methods: Cross-sectional population study to determine VitD levels in healthy subjects. The EPIRCAN study screen was used, a population study carried out between 2004 and 2005 to determine the prevalence of rheumatic diseases in the Canary Islands. In 949 serums, the levels of VitD, phosphorus and calcium were determined, as well as Parathyroid hormone (PTH), only in which calcium levels were $>10,4 \mathrm{mg} / \mathrm{dl}$. Data were analysed according to demographic characteristics, comorbidities and medication. For the statistical analysis the SPSS was used.

Results: The sociodemographic characteristics (age, sex and rural/urban population) of the 949 samples were representative of the Canarian population in the period studied according to data of the ISTAC (Canary Institute of Statistics) with a level of accuracy of $0.7 \mathrm{ng} / \mathrm{ml}$ for the vitD and a confidence level of $95 \%$. Healthy ( $\mathrm{n}=876,92.3 \%)$ and sick subjects $(n=73,7.7 \%)$ (renal failure, dialysis, Crohn's, ulcerative colitis, osteoporosis, calcium supplements, vitD, bisphosphonates or calcitonin). The median and Interquartile range of vitD levels in the entire population studied was 26.3 (20.9$32.9) \mathrm{ng} / \mathrm{ml}$. The VitD levels distribution of healthy population was: $66 \%$ were below $30 \mathrm{ng} / \mathrm{ml}, 23 \%$ were below $20 \mathrm{mg} / \mathrm{ml}$ and $4 \%$ were below $12,5 \mathrm{ng} / \mathrm{ml}$. According to the age groups, sex and location: women versus men have $2.8 \mathrm{ng} / \mathrm{ml}$ less VitD (Cl95\%: $1.487 ; 4.177)$. As the age increases the VitD values decrease; those aged $20-45$ with respect to $\geq 65$ years have $5.5 \mathrm{ng} / \mathrm{ml}$ more (Cl95\%: $3.574 ; 7.592)$, those $45-65$ years old have $2.397 \mathrm{ng} / \mathrm{ml}$ more $(\mathrm{Cl} 195 \% 0.255 ; 4.539)$ with respect to $\geq 65$ years, being statistically significant. There were no significant differences between the rural and urban population. The prevalence of hyperparathyroidism hypercalcemic was $0.2 \%$. Conclusion: In the healthy population, baseline levels of VitD are higher in men than in women and tend to decrease with age. Due to the distribution of VitD levels in a healthy population, in an area of high sun exposure, seems to be more reasonable to establish the optimal VitD levels in the general population at $20 \mathrm{ng} /$ $\mathrm{ml}$ instead of the established $30 \mathrm{mg} / \mathrm{ml}$.

References:

[1] F. Wu et al. Cut-points for associations between vitamin D status and multiple musculoskeletal outcomes in middle-aged women. (2017). Osteoporosis International; Volume 28, Issue 2, pp 505-515.

[2] E. Manson, J. (2016). Vitamin D Deficiency - Is There Really a Pandemic? The New England Journal of Medicine, pp.75;19.

Disclosure of Interests: None declared

DOI: 10.1136/annrheumdis-2020-eular.4928

\section{FRI0578 \\ DEVELOPMENT OF A MOBILE APP AND WIRELESS SENSORS SYSTEM TO ASSESS SPINAL MOBILITY IN AXIAL SPONDYLOARTHRITIS: PRELIMINARY} RESULTS.

J. L. Garrido-Castro ${ }^{1}$, F. Torres Vidal' ${ }^{1}$, M. Ladehesa Pineda ${ }^{2}$, M. D. C. Castro Villegas $^{2}$, I. C. Aranda-Valera ${ }^{2}$, R. Ortega Castro ${ }^{2}$, C. Gonzalez-Navas ${ }^{1}$, E. Collantes Estevez ${ }^{2}$ on behalf of COSPAR study group. ${ }^{1}$ Maimónides Biomedical Research Institute of Córdoba, Cordoba, Spain; ${ }^{2}$ Reina Sofia University Hospital, Rheumatology Service, Cordoba, Spain

Background: Spinal mobility is an important assessment outcome in axial spondyloarthritis (axSpA). Until now, conventional metrology (Schober test, lateral flexion, BASMI, ...) has been used to assess spinal mobility, however, new technologies have been developed that provide better accuracy, reliability and responsiveness. Motion capture has been validated and Inertial Measurement Unit (IMU) sensors, appears to be a promising alternative. To use this IMU sensors in axSpA patients, wireless systems must be developed and validated allowing to doctors and patients to use them in hospitals and at home.

Objectives: To develop an easy to use mobile app and IMU sensors system for analyse mobility for axSpA patients.

Methods: A mobile app has been developed (iUCOTrack) that communicates with two IMU sensors (Shimmer 3๑, Fig-a). These sensors are attached in different locations: at forehead and T12 for cervical mobility (Fig-c) and T12 and Sacrum for thoracolumbar mobility (Fig-b). The app provides mobility results for the different tests (Fig-d) and store results in the cloud. Validation tests of these sensors, using Matlab $\odot$, were done previously [1]. Our study test the validity of this app against a motion capture system, the UCOTrack®, and its metrology index, the UCOASMI [2], and conventional metrology as reference standards. Patiens with axSpA were recruited consecutively from the COSPAR cohort. Conventional metrology, PRO questionnaires and mobility (Cervical and thoracolumbar - flexion, lateral bending, rotation) using the iUCOTrack app and the UCOTrack were registered. Intraclasss Correlation Coefficients (ICC 3,1$)$ between systems and correlations (spearman) with other axSpA outcome measures were performed for testing validity.

Results: 15 axSpA patients ( $47 \%$ female, age $52 \pm 12$ years, disease duration $21 \pm 16$ years) were included. Table shows ROM (SD) in degrees obtained for cervical and thoracolumbar spine measured by motion capture (UCOTrack) and the app (iUCOTrack). In the last column appears the UCOASMI (SD) calculated using angles obtained by each system. All ICC were good (ICC $>0.8$ ), and correlations were significant $(p<0.05, r>0.8)$ specially the UCOASMI. Cervical rotation using a goniometer was $106.2 \pm 36^{\circ}$, with a significant correlation with both systems $(p<0.05 ; r>0.8)$. Schober correlation with lumbar flexion was poor (NS; $r>0.5)$ but a good correlation appeared with lateral flexion $(p<0.01 ; r>0.9)$. Mean BASM was $4.0 \pm 1.8$ with an excellent correlation with UCOASMI measured by Mocap $(\mathrm{p}<0.01 ; \mathrm{r}=0.93)$ and by IMU $(\mathrm{p}<0.001 ; \mathrm{r}=0.98)$.

\begin{tabular}{cccccccc}
\hline & Cervical & \multicolumn{4}{c}{ Thoracolumbar } \\
\hline Flex & Rot & Lat & Flex & Rot & Lat & UCOASMI
\end{tabular}

UCOTrack 79.5(24.7) $109.8(29.6) 62.5(25.1)$ 100.7(21.6) 61.8(25.3) 54.7(22.9) $6.07(1.66$ iUCOTrack 83.0(33.6) 112.6(44.3) 73.9(29.7) 114.4(28.1) 51.4(16.1) 59.4(15.4) 6.15(1.65) $\begin{array}{llllllll}\text { ICC } & 0.864 & 0.903 & 0.812 & 0.936 & 0.798 & 0.901 & 0.970\end{array}$

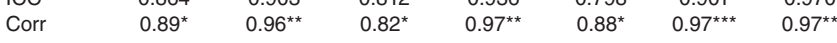

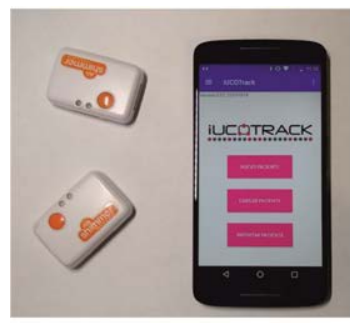

(a)

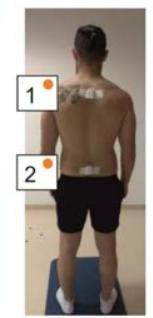

(b)

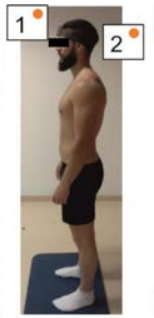

(c)

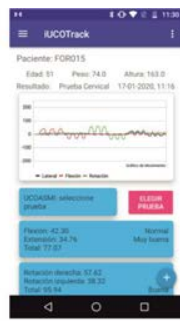

(d)
Conclusion: New metrology tools are needed to improve features of convencional metrology. Motion Capture has proved to be valid but has feasibility problems. IMU sensor based systems provide similar results to motion capture but it can be faster and cheaper. A system based on mobile app connected to wireless IMU sensors could be a solution to improve metrology in axSpA. Further studies and developments are needed to introduce these technologies in research and clinical daily practice. 